\title{
TCDD and omeprazole prime platelets through the aryl hydrocarbon receptor $(\mathrm{AhR})$ non-genomic pathway
}

\author{
Mónica Pombo ${ }^{\mathrm{a}}$, Michael W. Lamé ${ }^{\mathrm{b}}$, Naomi J. Walker ${ }^{\mathrm{c}}$, Danh H. Huynh ${ }^{\mathrm{a}}$, Fern Tablin ${ }^{\mathrm{a}, *}$ \\ a Department of Anatomy, Physiology \& Cell Biology, Davis, United States \\ ${ }^{\mathrm{b}}$ Department of Molecular Biosciences, Davis, United States \\ ${ }^{\mathrm{c}}$ Department of Pathology, Microbiology and Immunology, School of Veterinary Medicine, University of California, Davis, United States
}

\section{H I G H L I G H T S}

- A model of the platelet AhR non-genomic pathway is proposed.

- AhR activation by omeprazole or TCDD results in signaling through p38MAPK and CPLA 2 .

- TCDD and omeprazole prime platelets through increased sensitivity to physiological agonists.

\section{A R T I C L E I N F O}

\section{Article history:}

Received 17 December 2014

Received in revised form 28 February 2015

Accepted 16 March 2015

Available online 19 March 2015

\section{Keywords:}

AhR non-genomic pathway

Platelet priming

p38MAPK

$\mathrm{CPLA}_{2}$

Platelet signaling

\begin{abstract}
A B S T R A C T
The role of the aryl hydrocarbon receptor (AhR) in hemostasis has recently gained increased attention. Here, we demonstrate, by qRT-PCR and western blot, that human platelets express both AhR mRNA and AhR protein. AhR protein levels increase in a dose dependent manner when incubated with either 2,3,7,8tetrachlorodibenzo-p-dioxin (TCDD) or omeprazole. Treatment of platelets with puromycin blocks increased AhR protein synthesis in the presence of AhR activators. Additionally, treatment of platelets with either activator results in phosphorylation of p38MAPK and $\mathrm{CPLA}_{2}$, two key signaling molecules in platelet activation pathways. Using the AhR competitive inhibitors alpha naphthoflavone and $\mathrm{CH}-223191$, we show that phosphorylation of p38MAPK is AhR dependent. Further, inhibition of p38MAPK blocks downstream CPLA 2 phosphorylation induced by TCDD or omeprazole. Treatment with AhR activators results in platelet priming, as demonstrated by increased platelet aggregation, which is inhibited by AhR antagonists. Our data support a model of the platelet AhR non-genomic pathway in which treatment with AhR activators results in increased expression of the AhR, phosphorylation of p38MAPK and CPLA leading to platelet priming in response to agonist.
\end{abstract}

(c) 2015 Elsevier Ireland Ltd. All rights reserved.

\section{Introduction}

The aryl hydrocarbon receptor (AhR) is a highly conserved ligand-dependent transcription factor, belonging to the helix loop helix/PAS family of receptors. It is involved in detoxification pathways, and activation results in transcription of several xenobiotic response elements, including CYP1A1 and CYP1B1

Abreviations: TCDD, 2,3,7,8-tetrachlorodibenzo-p-dioxin; AhR, aryl hydrocarbon receptor; ARNT, aryl hydrocarbon receptor translocator; MAPK, mitogen activated protein kinase; $\mathrm{CPLA}_{2}$, cytosolic phospholipase $\mathrm{A}_{2}$; aNF, alpha naphthoflavone; $\mathrm{CH}$, CH-223192; SB, SB 202190; PRP, platelet rich plasma; $P_{1 / 2}$, prostaglandin $E_{1 / 2} ; A A$, arachidonic acid.

* Corresponding author. Tel.: +1 5307528259.

E-mail address: FTablin@ucdavis.edu (F. Tablin).
(Barouki et al., 2007). AhR ligands include dioxins, furans, polychlorinated byphenyls, tryptophan metabolites and benzimidazoles (Denison and Nagy, 2003). Many of these chemicals are environmentally persistent organic molecules, which represent a high risk to humans (Steenland et al., 2004). The halogenated aromatic hydrocarbon 2,3,7,8-tetrachlorodibenzo-p-dioxin (TCDD) is the most potent AhR ligand. Adverse effects resulting from TCDD exposure include developmental and reproductive toxicity, hepatic toxicity, tumor development, wasting syndrome and death (Fernandez-Salguero et al., 1996; Mimura and Fujii-Kuriyama, 2003). Omeprazole, a benzimidazole derivative, is a proton pump inhibitor used for the suppression of gastric acid secretion (Clissold and Campoli-Richards, 1986). It also is a recognized AhR activator, as evidenced by its ability to induce CYP1A1, CYP1B1 and other AhR-regulated genes (Jin et al., 2012; Shivanna et al., 2011), and is 
used to study the role of the AhR in cell differentiation, metastasis, inflammation and other biological processes (Jin et al., 2014).

Two AhR pathways have been characterized; the classical (genomic) pathway and the non-genomic pathway. In the classical pathway, upon ligand binding, the AhR translocates to the nucleus and heterodimerizes with the AhR nuclear translocator (ARNT) which initiates transcription of xenobiotic-responsive elements (Tompkins and Wallace, 2007). A second pathway, the AhR nongenomic pathway, does not involve translocation of the AhR to the nucleus, but instead results in a cascade of signaling events including phosphorylation of mitogen activated protein kinases (MAPKs), cytosolic phospholipase $\mathrm{A}_{2}\left(\mathrm{CPLA}_{2}\right)$ activation, increases in intracellular calcium, release of arachidonic acid (AA) and induction of inflammatory mediators (Matsumura, 2009). In nucleated cells, this pathway has been studied by mutating the AhR nuclear localization sequence thereby preventing AhR nuclear translocation (Vogel et al., 2007), as well as siRNA, blocking the formation of AhR/ARNT heterodimers required for initiation of transcription of xenobiotic response elements ( $\mathrm{Li}$ and Matsumura, 2008; Sciullo et al., 2008).

Platelets, anucleate cells, circulate in a resting state in the vasculature. Vascular injury results in platelet activation characterized by granule release, interaction with coagulation factors and the formation of a hemostatic plug. This process is highly regulated as sporadic activation can result in inappropriate thrombus formation, development of emboli, and eventual occlusion of critical blood vessels resulting in heart attack or stroke (Brass, 2003). Resting platelets can be primed for activation, such that they are more sensitive to physiological agonists. These primed platelets have an enhanced response to stimuli, and represent a risk for potential pathological thrombus formation and vessel occlusion (Gresele et al., 2008). A number of molecules prime platelets, and many manifest their activity by initiating intracellular signaling cascades (Blair et al., 2014; Falcinelli et al., 2005; Kowalska et al., 1994; Vezza et al., 1993). These priming events lead to circulating platelets that are more excitable, and who have increased responses to physiologic activation.

A recent study of the effects of TCDD on zebrafish thrombocytes, suggests a role for AhR signaling and the induction of thrombocyte activation (Kim et al., 2015). Studies by Lindsey et al. (2014) documented that AhR null mouse platelets have defective collagen mediated activation, as well as lower numbers of circulating platelets and increased bleeding times (Lindsey and Papoutsakis, 2011). These studies provide evidence for the emerging role of the AhR in platelet activation; yet the human platelet AhR signaling pathway remains to be defined.

Herein we describe the human platelet AhR non-genomic pathway and demonstrate that incubation with TCDD or omeprazole results in increased AhR protein synthesis, in the absence of increased AhR mRNA. We also show that binding of activator to the AhR initiates downstream signaling through the p38MAPK/CPLA 2 pathway, resulting in platelet priming as demonstrated by enhanced platelet aggregation in response to the thrombin receptor agonist SFLLRN.

\section{Materials and methods}

\subsection{Volunteers}

Samples were obtained from healthy volunteers between the ages of 18 and 65, who had not taken aspirin or any other nonsteroidal anti-inflammatory medication for at least 2 weeks prior to donation; following approved protocol (299969-3) by the Institutional Review Board of the University of California, Davis. All human volunteers provided a signed consent.

\subsection{Platelet preparation}

Blood samples were collected in either citrate-dextrose solution (ACD-A) or sodium citrate and stored at $37^{\circ} \mathrm{C}$ for up to $1 \mathrm{~h}$ prior to use. Platelet-rich plasma (PRP) was obtained by centrifuging whole blood $(325 \times g, 15 \mathrm{~min} R T)$. Washed platelets were prepared by centrifugation of PRP (with the addition of $10 \mu \mathrm{g} / \mathrm{ml}$ of $\mathrm{PGE}_{1}$ ) $(500 \times g, 24 \mathrm{~min})$, and the resulting platelet pellet suspended in Tyrode's-HEPES ( $12 \mathrm{mM} \mathrm{NaHCO}_{3}, 138 \mathrm{mM} \mathrm{NaCl}, 2.9 \mathrm{mM} \mathrm{KCl}, 10 \mathrm{mM}$ HEPES, $500 \mathrm{mM}$ dextrose, $\mathrm{pH}$ 7.2). Platelet counts were adjusted to $2 \times 10^{8}$ cells $/ \mathrm{ml}$ for all experiments, unless otherwise noted.

\subsection{Aggregometry}

PRP was generated as described above. Platelet concentrations for all aggregometry experiments were $\geq 2 \times 10^{6}$ cells $/ \mathrm{ml}$. PRP samples were pre-incubated with dimethyl sulfoxide (DMSO, vehicle control, Sigma-Aldrich), 2,3,7,8-tetrachlorodibenzo-p-dioxin (TCDD) (gift from Dr. Michael Dennison, University of California, Davis) or omeprazole (Sigma-Aldrich) $\left(1 \mathrm{~h} ; 37^{\circ} \mathrm{C}\right)$. Platelets were then stimulated with the protease-activated receptor 1 (PAR-1)(thrombin receptor) activator pepide SFLLRN $(10 \mu \mathrm{M})$ (Trocris Bioscience, Bristol, UK), and aggregation measured by optical aggregometry (Model 490ChronoLog Corporation, Havertown, PA). Slope and amplitude were calculated using ChronoLog software.

\subsection{Western blots}

Washed platelets were incubated with DMSO, TCDD or omeprazole $\left(37^{\circ} \mathrm{C} ; 1 \mathrm{~h}\right)$ or SFLLRN $\left(37^{\circ} \mathrm{C} ; 10 \mathrm{~min}\right)$. Samples were lysed in SDS-PAGE buffer, in the presence of protease inhibitors (leupeptin, pepstatin, trypsin inhibitor soybean, AESBSF and EDTA (Calbiochem, La Jolla, CA)), aprotinin (Sigma-Aldrich, St. Louis) and phosphatase inhibitors (Halt Phosphatase Inhibitor Cocktail, Thermo Fisher Scientific, Rockford, IL). Samples were separated by SDS-PAGE, transferred to nitrocellulose membranes, blocked with $5 \%(\mathrm{w} / \mathrm{v})$ dry non-fat milk in Tris-buffered saline-Tween 20 (TBST), and incubated overnight $\left(4^{\circ} \mathrm{C}\right)$ with the one of the following antibodies: AhR monoclonal (A-3, Santa Cruz Biotechnology, Santa Cruz, CA), p38MAPK polyclonal, monoclonal phospho-p38MAPK, polyclonal total cPLA 2 , polyclonal phospho$\mathrm{CPLA}_{2}$ or beta-actin (Cell Signaling Technology, Danvers, MA). Membranes were washed in TBST and incubated with either an anti-mouse (Santa Cruz Biotechnology) or anti-rabbit (Cell Signaling Technology) horseradish peroxidase conjugated antibody $(1 \mathrm{~h})$. Immunoblots were visualized by chemiluminescence (Super Signal West Femto Maximum Sensitivity Substrate, Thermo Fisher Scientific), according to manufacturer's protocol. Images were captured using Protein Simple FluorChem E System (Protein Simple, Santa Clara, CA) and densitometry was performed using Alpha View software, from Protein Simple. Beta actin served as a loading control. Blots were quantified by densitometry using either total p38MAPK or total CPLA 2 to evaluate relative phosphorylation.

\subsection{Inhibition studies}

Washed platelets or PRP were incubated with the competitive AhR antagonists alpha naphthoflavone (aNF, $5 \mu \mathrm{M}$ ) or $\mathrm{CH}-223191$ $(\mathrm{CH}, 10 \mu \mathrm{M})$ (Sigma-Aldrich) concomitantly with TCDD $\left(1 \mathrm{~h} ; 37^{\circ} \mathrm{C}\right)$. Samples were then prepared for western blot analysis or aggregometry as described above. p38MAPK inhibition of washed platelets was conducted with SB 292190 (SB, 20 MM) (Sigma-Aldrich) ( $10 \mathrm{~min})$, followed by the addition of TCDD ( $1 \mathrm{nM})$ or omeprazole $(100 \mathrm{nM})\left(1 \mathrm{~h} ; 37^{\circ} \mathrm{C}\right)$. To inhibit protein translation, washed platelets 
were incubated with puromycin (In VivoGen-San Diego, CA), (2 h; $\left.37^{\circ} \mathrm{C}\right)$; followed by the addition of DMSO, TCDD $(1 \mathrm{nM})$ or omeprazole $(100 \mathrm{nM})\left(1 \mathrm{~h} ; 37^{\circ} \mathrm{C}\right)$.

\subsection{Calcium measurement}

PRP was generated as described above, diluted in 50\% Tyrode'sHepes buffer and incubated for 60 min with Fluo-4 NW $\left(37^{\circ} \mathrm{C}\right)$ (Invitrogen, Carlsbad, CA) per the manufacturer's instructions. To determine immediate effect of omeprazole on calcium levels, omeprazole ( $10 \mathrm{nM}, 100 \mathrm{nM}$ ) was added to Fluo 4-NW loaded PRP and relative fluorescence was measured for $250 \mathrm{~s}$.
To determine if longer incubation with omeprazole $(1 \mathrm{~h})$ altered relative calcium levels, omeprazole or DMSO were added concomitantly with Fluo-4NW, samples were incubated $\left(37^{\circ} \mathrm{C}\right.$; $1 \mathrm{~h}$ ) and relative fluorescence measured. Additional aliquots were stimulated with SFLLRN $(10 \mu \mathrm{M})$ and relative fluorescence was measured for $250 \mathrm{~s}$. TCDD was not examined due to the significant risk of exposure.

All samples were read in a 96 well plate, and baseline relative fluorescence for each well was measured prior to stimulation or omeprazole addition; each condition was run in duplicate. Fluorescence was measured using a Synergy HT Multi-Mode microplate reader with Gen5 software (Biotek, Winooski, VT).
A
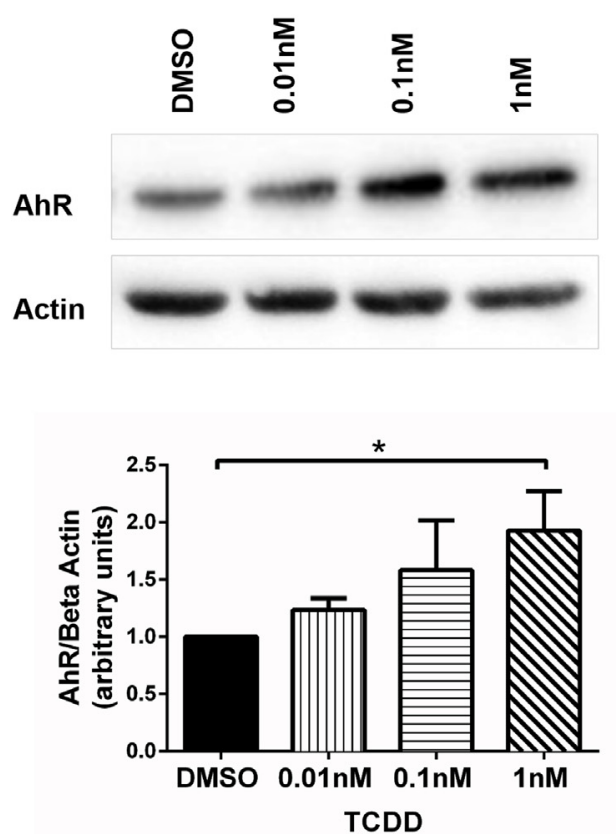

B
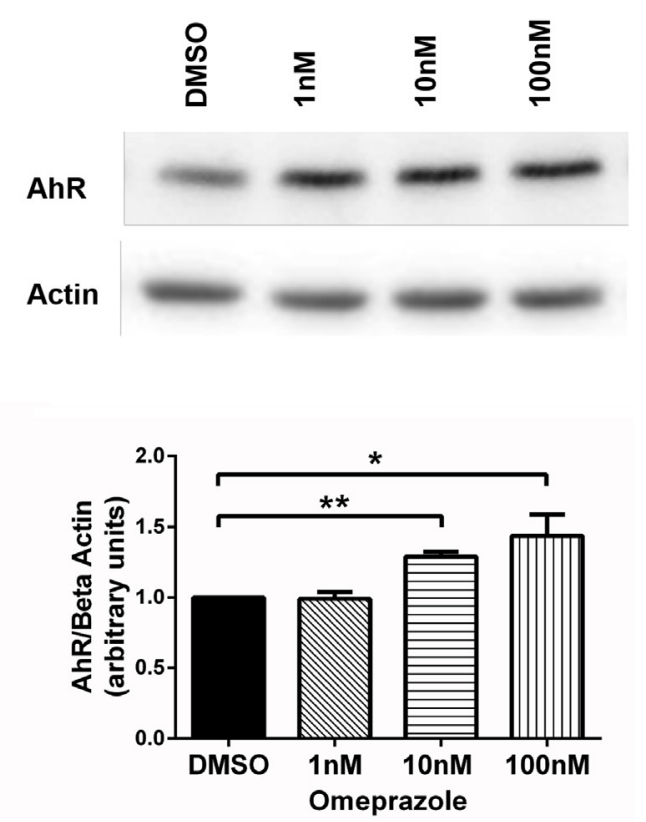

C
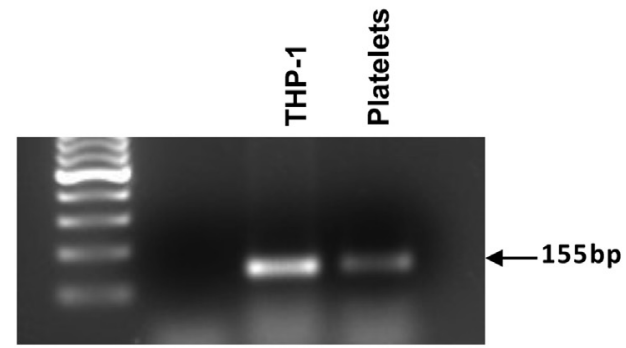

D

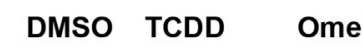

AhR

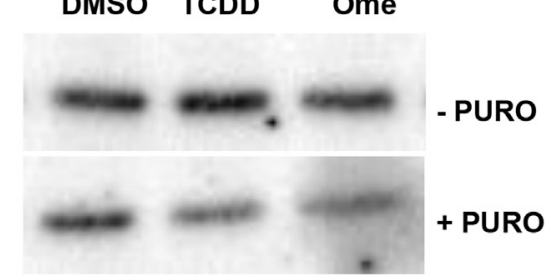

Fig. 1. Characterization of human platelet AhR: TCDD or omeprazole incubation results in a dose dependent increase in AhR expression.

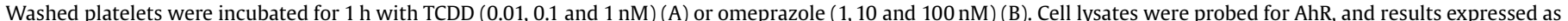

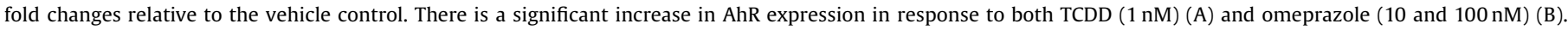
Representative results, $n=4$.

qRT-PCR products were run on an agarose gel, and compared with AhR message from THP-1 cells (positive control) (C).

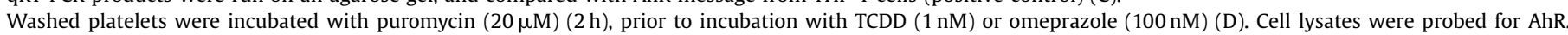
Representative results, $n=3 .-!>$ 


\subsection{RNA isolation and quantitative RT PCR anlaysis}

Washed platelets were further purified by removal of contaminating red or white blood cells following a modification of the method by Amisten (2012). Washed platelet suspensions were incubated with CD235a and CD45 (mouse anti-human; BD Pharmigen, Franklin Lakes, NJ) antibody coated magnetic beads (Dynabeads-Pan Mouse IgG; Life Technologies, Grand Island, NY) $(2 \mathrm{~h})$ to immuno-deplete residual red blood cells and leukocytes (respectively). Purified platelet suspensions were dissolved in TRIzol (Life Technologies); the aqueous layer from the previous extraction was added to an equal volume of $70 \%$ ethanol and RNA was extracted using RNeasy Mini Kit (Qiagen, Valencia, CA), according to manufacturer's instructions. cDNA was synthesized from isolated RNA using Superscript III and random primers (Invitrogen-Life Technologies). To examine AhR mRNA expression in human platelets, qRT PCR was performed using the AhR forward primer: TCCACCTAGTTGGTTTGTTTGC, reverse primer: TCGTGCACAGCTCTGCTTCAGTAT designed with Integrated DNA Technologies (IDT online software). cDNA from cultured THP-1 cells, a human monocytic cell line shown to have mRNA for AhR (Komura et al., 2001), was used as a positive control. Products of the PCR reaction were loaded on a $2 \%$ agarose gel for visualization. Amplicon size was confirmed using GeneRuler 100 bp Plus DNA Ladder (Thermo Fisher Scientific). To evaluate the relative changes in mRNA expression, purified platelet suspensions were incubated with DMSO or TCDD $(1 \mathrm{nM})\left(1 \mathrm{~h} ; 37^{\circ} \mathrm{C}\right)$; RNA isolated and cDNA synthesized, as described above. AhR mRNA expression was measured and normalized to beta actin using the forward primer: CTGTCCACCTTCCAGCAGATGT, reverse primer: CGCAACTAAGTCATAGTCCGCC. Real-time PCR assays were performed in triplicate with SYBR Green PCR MasterMix (Applied Biosystems, Warrington,
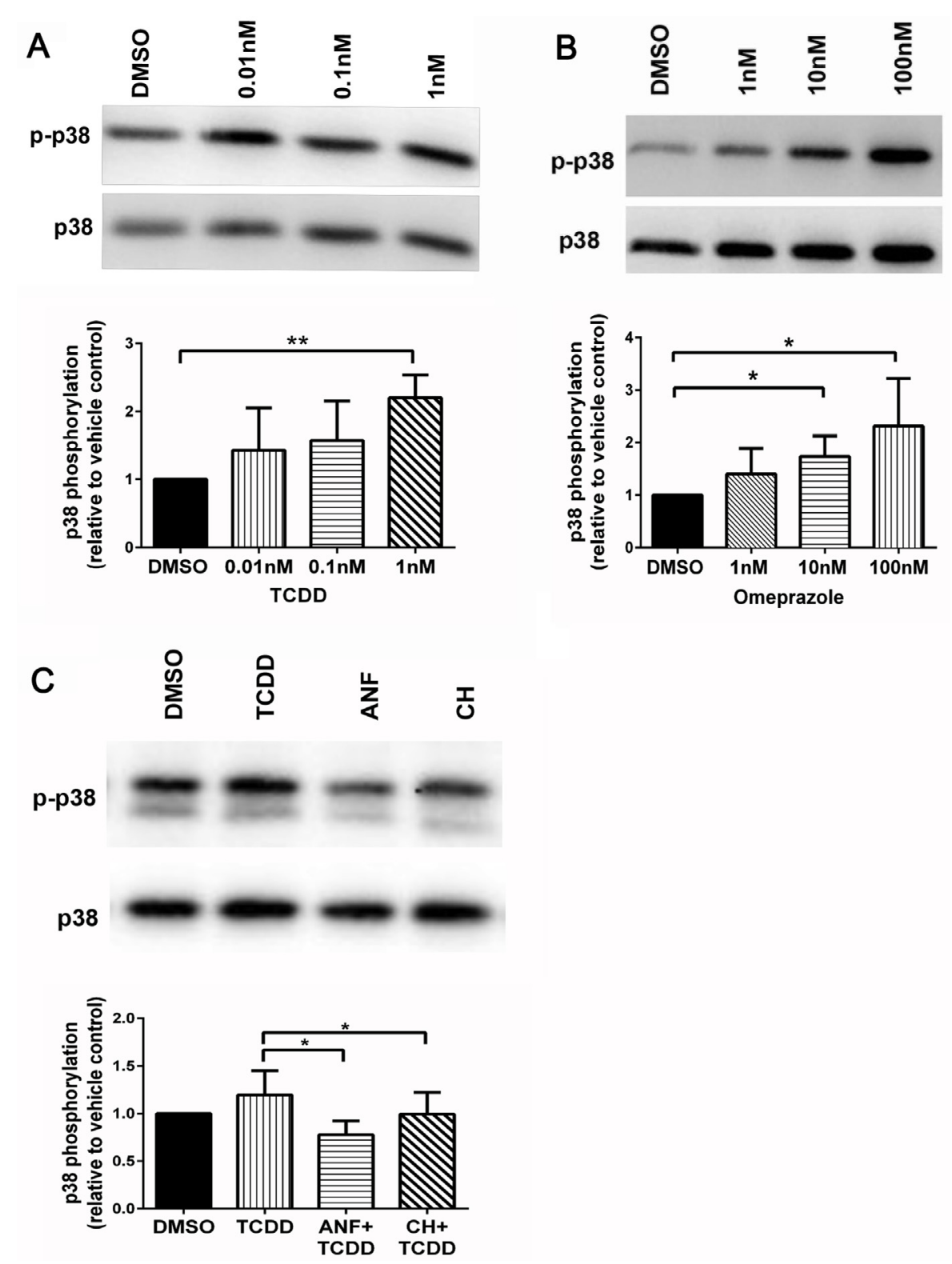

Fig. 2. AhR downstream signaling: incubation with TCDD or omeprazole result in AhR dependent p38MAPK phosphorylation.

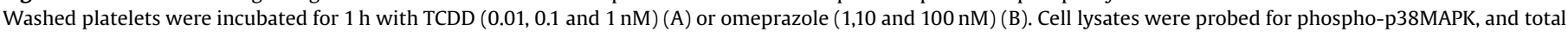

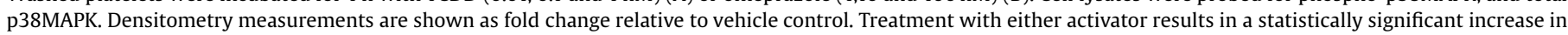
phosphorylation of p38MAPK.

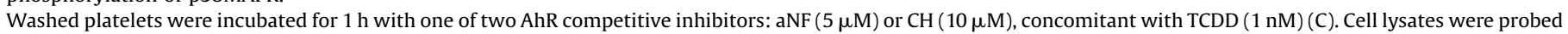

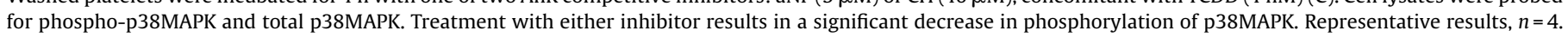


UK) on an Applied Biosystems 7300 Real-time PCR System. The cycling conditions were as follows: $50^{\circ} \mathrm{C}$ for $2 \mathrm{~min}, 95^{\circ} \mathrm{C}$ for $10 \mathrm{~min}$ followed by 40 cycles of $95^{\circ} \mathrm{C}$ for $15 \mathrm{~s}$, and $60^{\circ} \mathrm{C}$ for $1 \mathrm{~min}$. All realtime PCR assays were followed by a dissociation step (melt curve). The comparative threshold cycle $(\mathrm{Ct})$ method was used to calculate relative changes in gene expression determined from real-time quantitative PCR experiments (7300 system software, Applied Biosystems).

\subsection{Statistical analyses}

Data that were normally distributed were analyzed either by paired $t$-test or ANOVA. Data that were not normally distributed were analyzed by Wilcoxon signed rank test or Friedman test. A $p$ value $<0.05$ was considered to be statistically significant (GraphPad Prism 6.0). $\left({ }^{*} p<0.05,{ }^{* *} p<0.01\right)$

\section{Results}

\subsection{Characterization of the human platelet AhR}

To determine the human platelet AhR response to TCDD or omeprazole, washed human platelets were incubated with increasing concentrations of AhR activator, and AhR protein expression measured by western blot. Our data showed that AhR protein expression levels increased with increasing doses of either TCDD or omeprazole (Fig. 1A and B), and were statistically significant for both TCDD ( $1 \mathrm{nM})$ and omeprazole (10 $\mathrm{nM}$ and $100 \mathrm{nM})$.

Platelets are anucleate cells, however, they contain mRNA and functional machinery for protein synthesis (Zimmerman and Weyrich, 2008). Our western blot results demonstrated increased levels of AhR protein in response to activators, thus we wanted to determine whether there were changes in mRNA levels in response to TCDD. Using qRT-PCR, we determined that human platelets had AhR mRNA. To visually confirm that our amplicon product was the correct size ( $155 \mathrm{bp})$, qRT-PCR reaction products were run on an agarose gel, using THP- 1 cell cDNA as a positive control (Komura et al., 2001) (Fig. 1C). Platelet incubation with TCDD did not alter mRNA expression levels ( $\Delta \Delta \mathrm{Ct}: 1.01, n=3$ ), suggesting that the AhR protein increase observed after incubation with TCDD was likely the result of protein translation. Incubation of platelets with the protein translation inhibitor puromycin, prior to the addition of TCDD or omeprazole, resulted in attenuation of the AhR protein increase previously seen after incubation with either activator (Fig 1D).

\subsection{Ligand dependent downstream signal transduction}

To characterize the downstream signaling of the AhR nongenomic pathway, we evaluated phosphorylation of p38MAPK, an important molecule in multiple platelet activation pathways
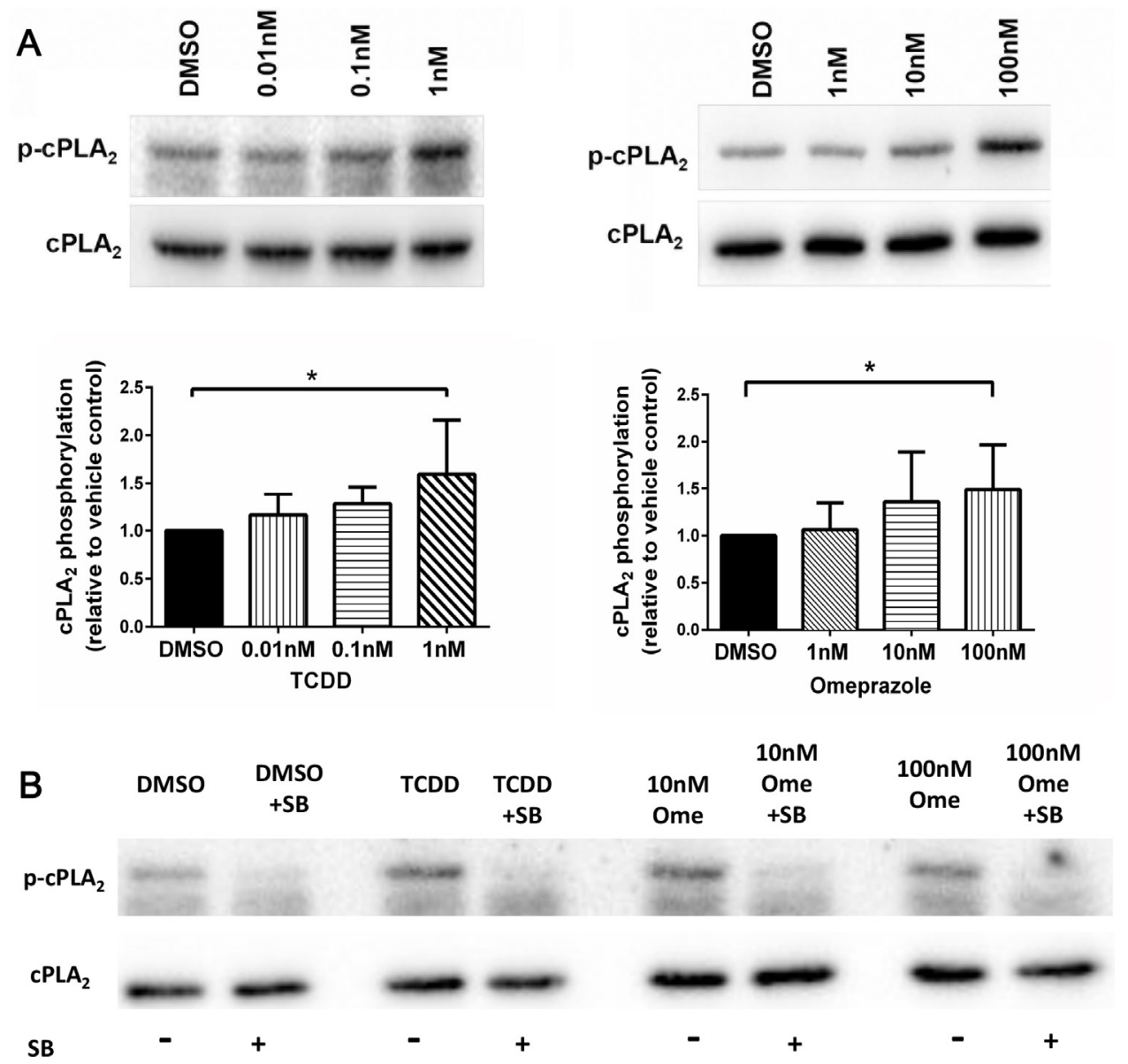

Fig. 3. TCDD and omeprazole induce $C P L A_{2}$ phosphorylation downstream of p38MAPK.

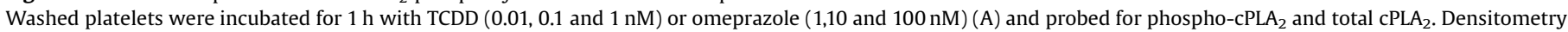

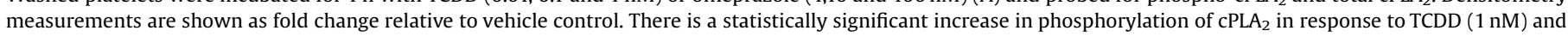
omeprazole ( $100 \mathrm{nM}$ ). Representative results, $n=4$.

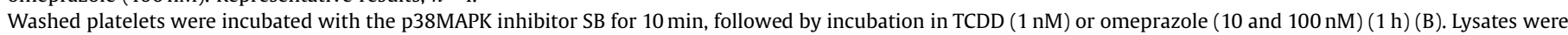
probed for phospho-cPLA $A_{2}$ and total CPLA $_{2}$. Virtually no phosphorylation of $\mathrm{CPLA}_{2}$ was observed. Representative results, $n=3$. 
(Kramer et al., 1996; Kuliopulos et al., 2004), and a protein shown to be involved in AhR non-genomic signaling (Henklova et al., 2008). Platelets incubated with increasing concentrations of AhR activators, TCDD $(1 \mathrm{nM})$ or omeprazole (10 nM and $100 \mathrm{nM})$ resulted in statistically significantly increased p38MAPK phosphorylation (Fig. 2A and B). To confirm that p38MAPK phosphorylation was dependent on AhR ligand binding, washed platelets were incubated with one of two competitive AhR antagonists, aNF or CH (Denison and Nagy, 2003) in the presence of TCDD. Our results demonstrated a statistically significant decrease in p38MAPK phosphorylation under these conditions (Fig. 2C).

In platelet activation, p38MAPK activation is associated with downstream cPLA 2 phosphorylation (Kramer et al., 1996); thus we wished to determine the effects of TCDD and omeprazole on $\mathrm{CPLA}_{2}$ phosphorylation. Platelets incubated with increasing concentrations of TCDD or omeprazole had a statistically significant dose dependent increase in $\mathrm{CPLA}_{2}$ phosphorylation ( $1 \mathrm{nM}$ TCDD and $100 \mathrm{nM}$ omeprazole) (Fig. $3 \mathrm{~A}$ ). To confirm that $\mathrm{CPLA}_{2}$ phosphorylation was dependent on p38MAPK phosphorylation, platelets were incubated with the p38MAPK specific inhibitor SB (Wilson et al., 1997). cPLA 2 phosphorylation was absent in platelets incubated with SB compared to platelets incubated only with AhR activator (Fig. 3B).

In platelets, agonist stimulation results in a rapid rise in intracellular calcium, which is essential for platelet activation (Detwiler et al., 1978). We wished to determine if omeprazole would have a similar effect on intracellular calcium. Intracellular calcium levels, determined by changes in relative fluorescence emission, were measured in Fluo-4 loaded platelets. PRP incubated with omeprazole had comparable relative fluorescence levels to PRP incubated with DMSO vehicle control (Relative Fluorescence Units (RFU) DMSO: 13,002 \pm 1028 ; $10 \mathrm{nM}$ omeprazole: $12,857 \pm 688.3 ; 100 \mathrm{nM}$ omeprazole: $13,269 \pm 804.3 ; p=0.4306$ ) (Fig. 4A). Calcium increases resulting from stimulation with SFLLRN were not significantly enhanced by pre-incubation of PRP with either $10 \mathrm{nM}$ or $100 \mathrm{nM}$ omeprazole, compared with a DMSO control (area under the curve (AUC) DMSO: $4.037 \mathrm{e}+006 \pm 368,666$; $10 \mathrm{nM}$ omeprazole: $4.065 \mathrm{e}+006 \pm 407,499 ; \quad 100 \mathrm{nM}$ omeprazole: $4.040 \mathrm{e}+006 \pm 375,221 ; p \geq 0.999$ ) (Fig. 4B). The initial addition of omeprazole did not result in a transient calcium rise (Fig. 4C).

\subsection{Platelet priming}

Platelet priming, defined as an increased sensitivity to physiologic agonists, can be evaluated by aggregometry. PRP was incubated with control vehicle, TCDD or omeprazole, then stimulated with SFLLRN and activation measured by optical aggregometry. Our results showed that samples incubated with either AhR activator had increased platelet aggregates as evidenced by a decrease in optical absorbance (Fig. 5A and B). The rates of aggregation (slope) and the percent maximum aggregation (amplitude) were statistically significantly greater than controls. Treatment of PRP with the AhR antagonist aNF (Fig. 5C), or the p38MAPK inhibitor SB (data not shown; $p<0.05$ ), significantly inhibited the priming effects of TCDD.

Platelet stimulation by physiologic agonist can induce protein synthesis of a number of signaling proteins (Zimmerman and Weyrich, 2008). Our results showed that incubation with AhR activator resulted in increased AhR protein levels (Fig. 1). Thus we wished to know if platelet stimulation with SFLLRN would result in increased AhR protein expression. We found that AhR expression was not up-regulated after incubation with SFLLRN (10 $\mu \mathrm{M}, 20 \mu \mathrm{M}$ or $40 \mu \mathrm{M}$ ) (Fig. 6).
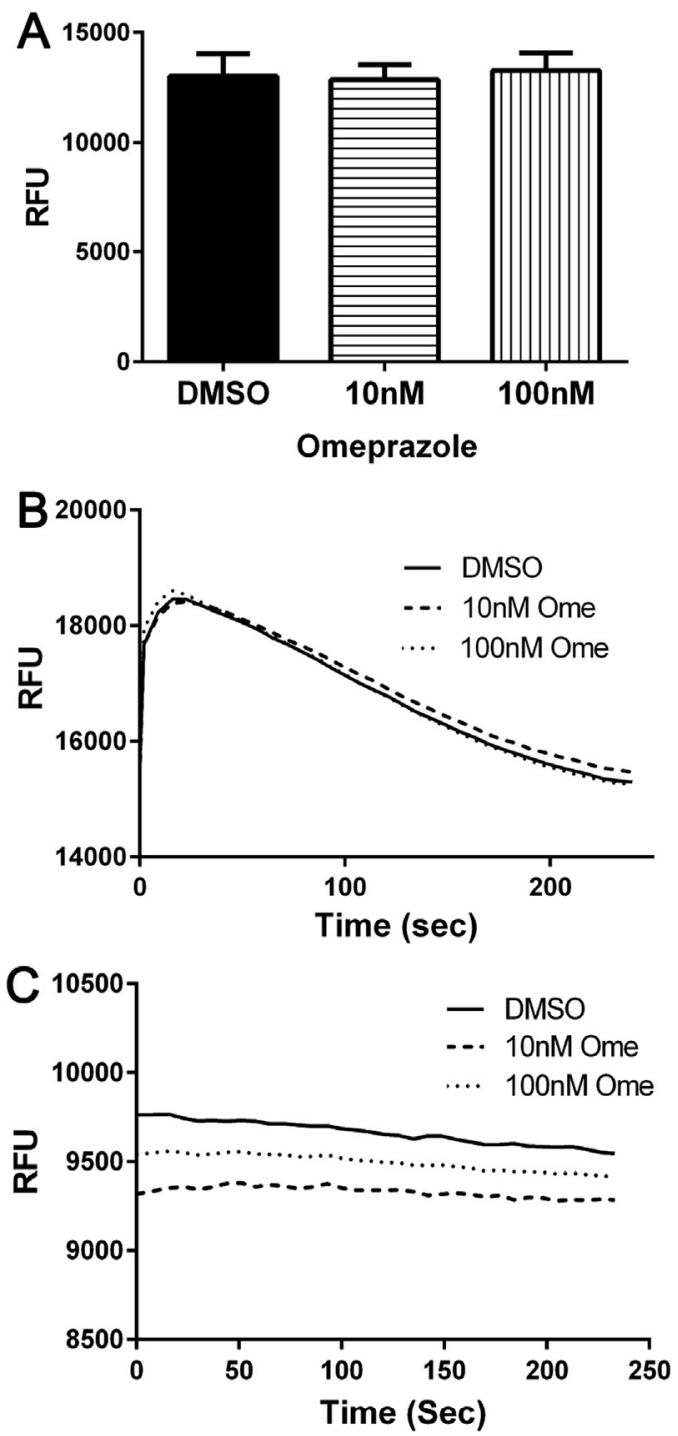

Fig. 4. Omeprazole incubation does not alter relative intracellular calcium levels. PRP was loaded with Fluo-4NW and incubated for $1 \mathrm{~h}$ with DMSO or omeprazole (10 and $100 \mathrm{nM})$. Intracellular calcium levels were measured by relative fluorescence after $1 \mathrm{~h}(\mathrm{~A})$. There was no difference in relative calcium levels between samples incubated with omeprazole or DMSO.

PRP samples pre-incubated with omeprazole (10 and $100 \mathrm{nM})$ or DMSO were stimulated with SFLLRN $(10 \mu \mathrm{M})$ and relative fluorescence was measured for $250 \mathrm{~s}$ (B). There was no statistical difference in calcium rise between omeprazole and DMSO samples. (C) Omeprazole addition to Fluo-4NW loaded PRP, and measured for $250 \mathrm{~s}$, did not show a change in relative fluorescence. Note that lag time from addition of SFLLRN to first read was $7 \mathrm{~s}$. Representative results, $n=4$.

\section{Discussion}

Our study describes the AhR non-genomic pathway in human platelets, and demonstrates that platelets have mRNA for AhR, and that AhR protein is increased when platelets are incubated with the AhR activators TCDD or omeprazole. Platelets are anucleate cells, yet several laboratories have demonstrated the physiologic relevance of protein translation in platelet activation (Zimmerman and Weyrich, 2008). Platelet stimulation with the physiological agonist thrombin induces synthesis of proteins such as Bcl-3, an important protein in integrin dependent platelet activation, and Il$1 \beta$, a pro-inflammatory cytokine secreted after platelet stimulation (Lindemann et al., 2001; Weyrich et al., 1998). We show that incubation with the AhR activators TCDD or omeprazole is sufficient to induce increased AhR protein synthesis, which is 

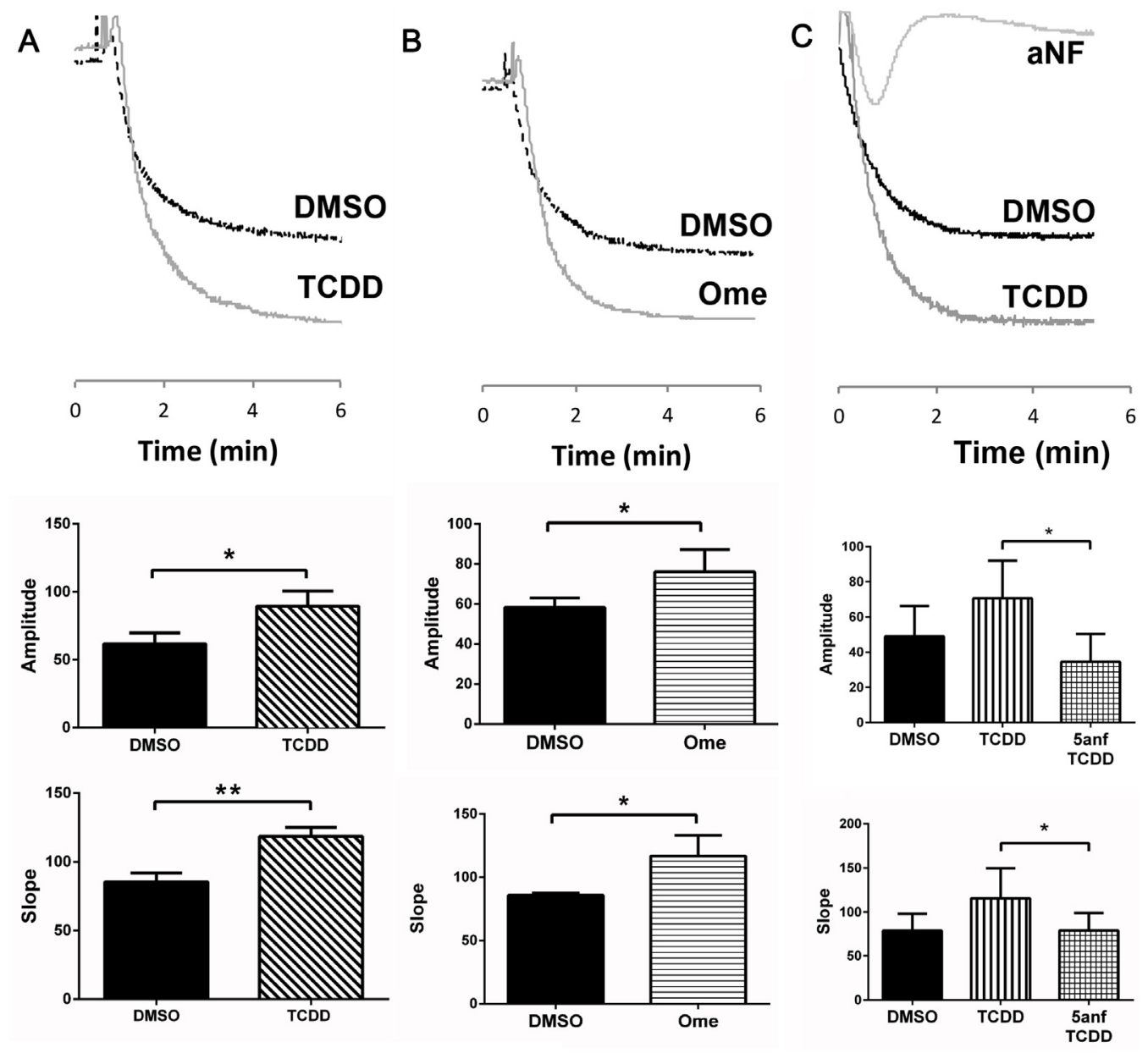

Fig. 5. AhR activation results in enhanced aggregation in response to SFLLRN which can be inhibited by the AhR antagonist aNF.

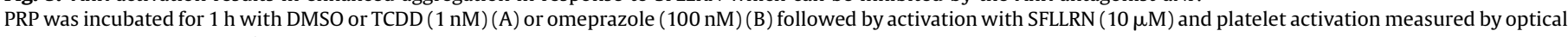
aggregometry. Representative aggregometry curves, $n=4$.

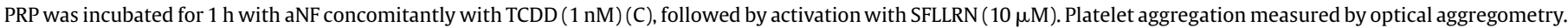
Representative aggregometry curves $n=5$. ANF significantly decreases enhanced platelet aggregation.

inhibited by puromycin. Unlike the studies of Weyrich et al., platelet stimulation by the thrombin analogue SFLLRN does not increase AhR expression.

Incubation of human platelets with AhR activators results in a dose and AhR dependent increase in p38MAPK phosphorylation. During physiologic activation by agonists such as thrombin and SFLLRN, p38MAPK is phosphorylated and plays an important role in platelet signaling (Kuliopulos et al., 2004). Activation of p38MAPK in the AhR non-genomic pathway appears to be cell type-specific. In rat hepatoma cells, incubation with TCDD results in AhR dependent p38MAPK phosphorylation (Weiss et al., 2005), yet, in murine macrophages, TCDD induced p38MAPK activation was independent of the AhR (Park et al., 2005).

We show that incubation with TCDD or omeprazole results in CPLA 2 phosphorylation, which is dependent on p38MAPK. During platelet activation, $\mathrm{CPLA}_{2}$ phosphorylation is downstream of p38MAPK, and its activation mediates movement of AA from the plasma membrane to the cytosol (Kramer et al., 1996). CPLA 2 also can be transiently activated by increases in intracellular calcium (Leslie et al., 2010). In the AhR non-genomic pathway, incubation with AhR activator results in transient CPLA $A_{2}$ phosphorylation which is associated with a rise in intracellular calcium (Dong et al., 2010; Li and Matsumura, 2008; Sciullo et al., 2008). However, in human platelets, treatment with omeprazole did not alter intracellular calcium levels. Our results suggest that in human platelets, transient $\mathrm{CPLA}_{2}$ phosphorylation via the AhR nongenomic pathway is primarily mediated by p38MAPK.

Platelet activation initiates signaling events culminating in granule secretion, platelet aggregation and the development of a pro-coagulant environment (Brass, 2003), critical for the development of a physiologically stable thrombus (Jarvis, 2004). Platelets incubated with AhR activators and subsequently stimulated with SFLLRN showed enhanced platelet aggregation, suggesting that binding these AhR activators to the AhR prime platelets. Platelet priming occurs when cells are exposed to a compound that by itself does not induce activation, but which leads to an enhanced cellular response to physiological stimuli (Gresele et al., 2008).

\section{SFLLRN}

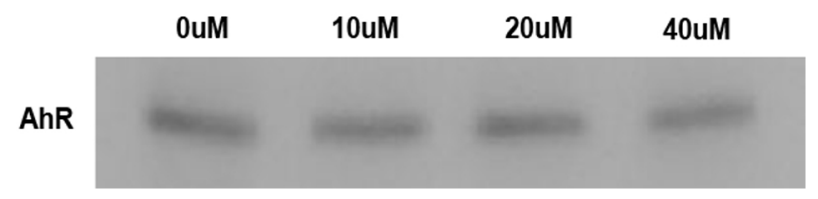

Fig. 6. SFLLRN stimulation does not result in an increase in AhR protein expression. Washed platelets were stimulated with increasing doses of the SFLLRN $(10 \mu \mathrm{M}$, $20 \mu \mathrm{M}$ or $40 \mu \mathrm{M})(10 \mathrm{mins})$. Cell lysates were probed for AhR. There was no change in protein expression in response to SFLLRN stimulation. Representative results, $n=3$. 
Several molecules prime platelets by initiating signaling prior to physiological agonist stimulation. Platelet derived $\mathrm{PGE}_{2}$, matrix metalloproteinase-2 (MPP-2), insulin-like growth factor 1 (IGF-1), and histamine potentiate platelet responses by modulating signaling proteins such as protein kinase $\mathrm{C}$ (PKC), phosphatidylinositol 3-kinase (PI3-K) and p38MAPK respectively. (Blair et al., 2014; Falcinelli et al., 2005; Shah et al., 2000; Vezza et al., 1993). Our study shows that activation of the AhR leads to phosphorylation of p38MAPK and transient activation of $\mathrm{CPLA}_{2}$ resulting in platelet priming.

Our studies may shed light on the current clinical conundrum regarding the combined therapeutic use of omeprazole and the platelet purinergic receptor inhibitor clopidogrel. Clopidogrel, a prodrug metabolized by cytochrome P450s, is frequently prescribed together with omeprazole, to prevent gastrointestinal bleeding. Importantly, several reports suggest that in patients receiving this combined therapy, clopidogrel's efficacy is diminished (Gilard et al., 2006; Pezalla et al., 2008). This decrease in clopidogrel's function is thought to be due to omeprazole's competitive inhibition of the CYP450 isoenzyme group (Cuisset et al., 2009; Gilard et al., 2008). Our data suggests an alternative scenario, in which omeprazole therapy, modulating platelet priming through the AhR, could upregulate platelet activation, resulting in a diminished response to clopidogrel therapy.

Overall, our data add to the increasing body of knowledge regarding the role of the AhR in platelet biology. Further studies are required to expand our understanding of the role of the human platelet AhR in hemostasis and thrombosis.

\section{Conflict of interest}

The authors declare that there are no conflicts of interest.

\section{Transparency document}

The Transparency document associated with this article can be found in the online version.

\section{Acknowledgments}

We thank Chadwick Hillman and Dr. Hnin Hning Aung for their assistance and Dr. Michael Denison for his guidance. These studies have been funded in part by the California Air Resources Board: contract 3 13-311 with the University of California Davis. The statements and conclusions in this study are those of the University of California Davis and are not necessarily those of the California Air Resources Board.

\section{References}

Amisten, S., 2012. A rapid and efficient platelet purification protocol for platelet gene expression studies. Methods Mol. Biol. 788, 155-172.

Barouki, R., Coumoul, X., Fernandez-Salguero, P.M., 2007. The aryl hydrocarbon receptor, more than a xenobiotic-interacting protein. FEBS Lett. 581, 3608-3615.

Blair, T.A., Moore, S.F., Williams, C.M., Poole, A.W., Vanhaesebroeck, B., Hers, I., 2014 Phosphoinositide 3-kinases p110alpha and p110beta have differential roles in insulin-like growth factor-1-mediated Akt phosphorylation and platelet priming. Arterioscler: Thromb. Vasc. Biol. 34, 1681-1688.

Brass, L.F., 2003. Thrombin and platelet activation. Chest 124, 18S-25S.

Clissold, S.P., Campoli-Richards, D.M., 1986. Omeprazole. A preliminary review of its pharmacodynamic and pharmacokinetic properties: and therapeutic potential in peptic ulcer disease and Zollinger-Ellison syndrome. Drugs 32, 15-47.

Cuisset, T., Frere, C., Quilici, J., Poyet, R., Gaborit, B., Bali, L., Brissy, O., Morange, P.E. Alessi, M.C., Bonnet, J.L., 2009. Comparison of omeprazole and pantoprazole influence on a high 150-mg clopidogrel maintenance dose the PACA (Proton Pump Inhibitors And Clopidogrel Association) prospective randomized study. J. Am. Coll. Cardiol. 54, 1149-1153.

Denison, M.S., Nagy, S.R., 2003. Activation of the aryl hydrocarbon receptor by structurally diverse exogenous and endogenous chemicals. Ann. Rev. Pharmacol. Toxicol. 43, 309-334.
Detwiler, T.C., Charo, I.F., Feinman, R.D., 1978. Evidence that calcium regulates platelet function. J. Thromb. Haemost. 40, 207-211.

Dong, B., Nishimura, N., Vogel, C.F., Tohyama, C., Matsumura, F., 2010. TCDD-induced cyclooxygenase-2 expression is mediated by the nongenomic pathway in mouse MMDD1 macula densa cells and kidneys. Biochem. Pharmacol. 79, 487-497.

Falcinelli, E., Guglielmini, G., Torti, M., Gresele, P., 2005. Intraplatelet signaling mechanisms of the priming effect of matrix metalloproteinase- 2 on platelet aggregation. J. Thromb. Haemost. 3, 2526-2535.

Fernandez-Salguero, P.M., Hilbert, D.M., Rudikoff, S., Ward, J.M., Gonzalez, F.J., 1996. Aryl-hydrocarbon receptor-deficient mice are resistant to 2,3,7,8tetrachlorodibenzo-p-dioxin-induced toxicity. Toxicol. Appl. Pharmacol. 140, $173-179$.

Gilard, M., Arnaud, B., Cornily, J.C., Le Gal, G., Lacut, K., Le Calvez, G., Mansourati, J., Mottier, D., Abgrall, J.F., Boschat, J., 2008. Influence of omeprazole on the antiplatelet action of clopidogrel associated with aspirin: the randomized, double-blind OCLA (Omeprazole CLopidogrel Aspirin) study. J. Am. Coll. Cardiol. 51, 256-260.

Gilard, M., Arnaud, B., Le Gal, G., Abgrall, J.F., Boschat, J., 2006. Influence of omeprazol on the antiplatelet action of clopidogrel associated to aspirin. J. Thromb. Haemost. 4, 2508-2509.

Gresele, P., Falcinelli, E., Momi, S., 2008. Potentiation and priming of platelet activation: a potential target for antiplatelet therapy. Trends Pharmacol. Sci. 29, 352-360.

Henklova, P. Vrzal, R., Ulrichova, J., Dvorak, Z, 2008. Role of mitogen-activated protein kinases in aryl hydrocarbon receptor signaling. Chem. Biol. Interact. 172, 93-104.

Jarvis, G.E., 2004. Platelet aggregation: turbidimetric measurements. Methods Mol. Biol. 272, 65-76.

Jin, U.H., Lee, S.O., Pfent, C., Safe, S., 2014. The aryl hydrocarbon receptor ligand omeprazole inhibits breast cancer cell invasion and metastasis. BMC Cancer 14 498.

Jin, U.H., Lee, S.O., Safe, S., 2012. Aryl hydrocarbon receptor (AHR)-active pharmaceuticals are selective AHR modulators in MDA-MB-468 and BT474 breast cancer cells. J. Pharmacol. Exp. Ther. 343, 333-341.

Kim, S., Sundaramoorthi, H., Jagadeeswaran, P., 2015. Dioxin-induced thrombocyte aggregation in zebrafish. Blood Cells Mol. Dis. 54, 116-122.

Komura, K., Hayashi, S., Makino, I., Poellinger, L., Tanaka, H., 2001. Aryl hydrocarbon receptor/dioxin receptor in human monocytes and macrophages. Mol. Cell. Biochem. 226, 107-118.

Kowalska, M.A., Juliano, D., Trybulec, M., Lu, W., Niewiarowski, S., 1994. Zinc ions potentiate adenosine diphosphate-induced platelet aggregation by activation of protein kinase C. J. Lab. Clin. Med. 123, 102-109.

Kramer, R.M., Roberts, E.F., Um, S.L., Borsch-Haubold, A.G., Watson, S.P., Fisher, M.J., Jakubowski, J.A., 1996. p38 mitogen-activated protein kinase phosphorylates cytosolic phospholipase A2 (cPLA2) in thrombin-stimulated platelets. Evidence that proline-directed phosphorylation is not required for mobilization of arachidonic acid by cPLA2. J. Biol. Chem. 271, 27723-27729.

Kuliopulos, A., Mohanlal, R., Covic, L., 2004. Effect of selective inhibition of the p38 MAP kinase pathway on platelet aggregation. J. Thromb. Haemost. 92 1387-1393.

Leslie, C.C., Gangelhoff, T.A., Gelb, M.H., 2010. Localization and function of cytosolic phospholipase A2alpha at the Golgi. Biochimie 92, 620-626.

Li, W., Matsumura, F., 2008. Significance of the nongenomic, inflammatory pathway in mediating the toxic action of TCDD to induce rapid and long-term cellular responses in 3T3-L1 adipocytes. Biochemistry 47, 13997-14008.

Lindemann, S., Tolley, N.D., Dixon, D.A., McIntyre, T.M., Prescott, S.M., Zimmerman, G.A., Weyrich, A.S., 2001. Activated platelets mediate inflammatory signaling by regulated interleukin 1beta synthesis. J. Cell Biol. 154, 485-490.

Lindsey, S., Jiang, J., Woulfe, D., Papoutsakis, E.T., 2014. Platelets from mice lacking the aryl hydrocarbon receptor exhibit defective collagen-dependent signaling. J. Thromb. Haemost. 12, 383-394.

Lindsey, S., Papoutsakis, E.T., 2011. The aryl hydrocarbon receptor (AHR) transcription factor regulates megakaryocytic polyploidization. Br. J. Haematol. 152, 469-484.

Matsumura, F., 2009. The significance of the nongenomic pathway in mediating inflammatory signaling of the dioxin-activated Ah receptor to cause toxic effects. Biochem. Pharmacol. 77, 608-626.

Mimura, J., Fujii-Kuriyama, Y., 2003. Functional role of AhR in the expression of toxic effects by TCDD. Biochim. Biophys. Acta 1619, 263-268.

Park, S.J., Yoon, W.K., Kim, H.J., Son, H.Y., Cho, S.W., Jeong, K.S., Kim, T.H., Kim, S.H., Kim, S.R., Ryu, S.Y., 2005. 2,3,7,8-Tetrachlorodibenzo-p-dioxin activates ERK and p38 mitogen-activated protein kinases in RAW 264.7 cells. Anticancer Res. 25, 2831-2836.

Pezalla, E., Day, D., Pulliadath, I., 2008. Initial assessment of clinical impact of a drug interaction between clopidogrel and proton pump inhibitors. J. Am. Coll. Cardiol. 52, 1038-1039 author reply 1039.

Sciullo, E.M., Vogel, C.F., Li, W., Matsumura, F., 2008. Initial and extended inflammatory messages of the nongenomic signaling pathway of the TCDD-activated Ah receptor in U937 macrophages. Arch. Biochem. Biophys. 480, 143-155.

Shah, B.H., Lashari, I., Rana, S., Saeed, O., Rasheed, H., Arshad Saeed, S., 2000. Synergistic interaction of adrenaline and histamine in human platelet aggregation is mediated through activation of phospholipase map kinase and cyclo-oxygenase pathways. Pharmacol. Res. 42, 479-483. 
Shivanna, B., Jiang, W., Wang, L., Couroucli, X.I., Moorthy, B., 2011. Omeprazole attenuates hyperoxic lung injury in mice via aryl hydrocarbon receptor activation and is associated with increased expression of cytochrome P4501A enzymes. J. Pharmacol. Exp. Ther. 339, 106-114.

Steenland, K., Bertazzi, P., Baccarelli, A., Kogevinas, M., 2004. Dioxin revisited: developments since the 1997 IARC classification of dioxin as a human carcinogen. Environ. Health Perspect. 112, 1265-1268.

Tompkins, L.M., Wallace, A.D., 2007. Mechanisms of cytochrome P450 induction. J. Biochem. Mol. Toxicol. 21, 176-181.

Vezza, R., Roberti, R., Nenci, G.G., Gresele, P., 1993. Prostaglandin E2 potentiates platelet aggregation by priming protein kinase C. Blood 82, 2704-2713.

Vogel, C.F., Nishimura, N., Sciullo, E., Wong, P., Li, W., Matsumura, F., 2007. Modulation of the chemokines KC and MCP-1 by 2,3,7,8-tetrachlorodibenzo- $p$ dioxin (TCDD) in mice. Arch. Biochem. Biophys. 461, 169-175.
Weiss, C., Faust, D., Durk, H., Kolluri, S.K., Pelzer, A., Schneider, S., Dietrich, C., Oesch, F., Gottlicher, M., 2005. TCDD induces c-jun expression via a novel Ah (dioxin) receptor-mediated p38-MAPK-dependent pathway. Oncogene 24, 4975-4983.

Weyrich, A.S., Dixon, D.A., Pabla, R., Elstad, M.R., McIntyre, T.M., Prescott, S.M., Zimmerman, G.A., 1998. Signal-dependent translation of a regulatory protein, Bcl-3, in activated human platelets. Proc. Natl. Acad. Sci. U. S. A. 95, 5556-5561.

Wilson, K.P., McCaffrey, P.G., Hsiao, K., Pazhanisamy, S., Galullo, V., Bemis, G.W. Fitzgibbon, M.J., Caron, P.R., Murcko, M.A., Su, M.S., 1997. The structural basis for the specificity of pyridinylimidazole inhibitors of p38 MAP kinase. Chem. Biol. 4, 423-431.

Zimmerman, G.A., Weyrich, A.S., 2008. Signal-dependent protein synthesis by activated platelets: new pathways to altered phenotype and function. Arterioscler. Thromb. Vasc. Biol. 28, s17-24. 